\title{
Internet Self-Efficacy in Writing Processes Task Performance
}

\author{
Amin Shahini ${ }^{1}$, Majid Nemati ${ }^{2}$ \\ ${ }^{1}$ Department of Languages and Literature, Science and Research Branch, Islamic Azad University, Tehran, Iran \\ ${ }^{2}$ Department of English Language and Literature, University of Tehran, Tehran, Iran \\ Email address: \\ shahiniamin@gmail.com (A. Shahini), Nematim@ut.ac.ir (M. Nemati) \\ To cite this article: \\ Amin Shahini, Majid Nemati. Internet Self-Efficacy in Writing Processes Task Performance. Education Journal. \\ Vol. 4, No. 3, 2015, pp. 132-138. doi: 10.11648/j.edu.20150403.16
}

\begin{abstract}
This paper investigates the impact of Internet Self-Efficacy on the process writing performance of EFL learners in two online environment - wiki and email. Forty male and female sophomores and juniors who were sitting a course on process writing participated in this study. The participants were randomly assigned to the wiki and email modules. The teacher required the wiki participants to write and post about given topics on the wiki and as for the email module the participants had to send their writing samples through email. In both modules, the participants were given feedback by the teacher in the email module and by the teacher and peers in the wiki. Each session each writing sample was rated by a writing process rating scale (Maftoon \& Akef, 2010). Meanwhile, an Internet Self-Efficacy Measure was also administered to both groups. Results indicated that there were positive and significant correlations between the stages of process writing and Internet self-efficacy. Discussions, suggestions, and implications for research and practice are proposed.
\end{abstract}

Keywords: Internet Self-Efficacy, Wiki, Email, Writing

\section{Introduction}

In recent decades, collaborative online activities have extended their path to different areas of ESL teaching. One of the ESL fields which has steadily grown in its importance and scope in online environments is ESL writing. A great body of recent literature has focused on the online teaching methodologies and environments that attempt to propose new ways of teaching this skill (e.g. Chao \& Lo, 2011; Kessler, 2009; Kost, 2011; Lee, 2010; Salaber, 2014). Most of these studies claim that the application of collaborative online writing tasks, carried out in a shared environment for discussing and working together improves writing performance by the provision of scaffolding through peer feedback, sharing of ideas, students' autonomy, and students' engagement in writing tasks (ibid). Collaborative writing whether online or conventional is, in essence, a form of collaborative learning. This view has long been supported by Vygotsky's (1978) social constructivism, stressing that collaboration is in the heart of any successful learning. This collaboration whether among peers or between peer and teacher is essential in assisting each student in fulfilling his or her task by advancing through his or her own zone of proximal development (ZPD) which is defined as the gap between what the learner could accomplish alone and what he or she could accomplish in cooperation with others who are more skilled or experienced (Chao \& Lo, 2011).

With the emergence of new technologies for collaborative writing such as wikis and also some less recent ones like emails, the concept of ZPD and its effect in successful learning has been revived once again, sparking a plethora of replicated studies this time in online environments with positive pro-online findings (e.g. Greenfield, 2003; Lee, 2010; Tharp, 2010; Salaber, 2014). However, it is not wise to select these environments for instructional purposes solely based on the desire for and the allure of new technologies (Hsu \& Chiu, 2004). Since instructional technologies are new to many students, they may face a great number of problems in their online activities. Novice learners, for instance, may feel apprehensive about using instructional technologies which, in turn, may endanger their intellectual interaction and their ability to succeed in online learning. Feeling alienated from the online environment, the learners have to squander more time figuring out what to do to be able to communicate with 
his or her teacher and peers, hand in online assignments, or download class-related materials from the course's webpage which consequently leaves little time to spend for the actual course content (Chang, Liu, Sung, Lin, Chen, \& Cheng, 2014; Flowers, 2011; Miltiadou \& Yo, 2000; Puzziferro, 2008). This can adversely affect learners' incentives to learn. Here, learners' beliefs and views of their talent and abilities play a key role in preventing them from further alienation from the course.

\section{Self-Efficacy and Online Performance}

Bandura (1997) argued that students' learning performance largely depends on their perception of their own abilities to fulfill a task or achieve certain goals, the perception of their motivation to explore, and their desire to learn; in other words, students' learning performance depends on their selfefficacy. Bandura defined self-efficacy as "an individual's judgment of the individual's capabilities to organize and execute courses of action required to attain designated types of performances" (Lee \& Medlinger, 2011, p. 244). Bandura further stated that people's self-efficacy determines their choices, aspirations, and the effort they exert in a given endeavor. Individuals who see themselves as self-efficacious tend to initiate an adequate effort that may result in successful outcomes, whereas those who don't perceive themselves as self-efficacious are likely to cease their efforts prematurely and fail in the task (Kim \& Kim, 2005). As for the internet environment, by the same token, self-efficacy refers to the individuals' judgment about their abilities to succeed when faced with problems in online settings such as wikis, emails, discussion boards, etc.

However, Marakas, Yi, and Johnson (1998) stated that internet self-efficacy (ISE) is different from general selfefficacy (GSE). They claimed that learners with high levels of ISE had better performance in online learning. But, learners with high levels of GSE were not necessarily better than learners with lower GSE in online tasks. Therefore, it seems that familiarity with technology and the related tools is a must when taking online courses. Once, learners become familiar with the technologies, they become more interested in online learning.

Many scholars corroborated the importance of ISE in online education (e.g. Lynch \& Dembo, 2004; Wang \& Newlin, 2002a, 2002b; Joo, Bong, \& Choi, 2000; Zhang, Li, Duan, \& Wu, 2001). Some studies also suggested that ISE highly affects learning motivation (Chang et al., 2014), learning acceptance and satisfaction (Lee \& Medlinger, 2011) and computer anxiety (Torkzadeh \& Van Dyke, 2001). Conversely, some studies have found that ISE cannot predict students' online learning outcomes (Bell, 2007; Xie, Debacker, \& Perguson, 2006). This paradox implies further studies to explore the depth of this issue are required.

However, as evident, most research studies have investigated the effect of ISE on limited aspects of online learning performance only, leaving the literature void of research on mainstream skills like writing processes. To date, few studies have investigated the relationship between EFL learners' ISE and their writing performance in two wikibased and email-based writing tasks. To this end, the following research hypothesis will be tested.

H1: ISE is significantly correlated with learners' performance in wiki module.

H2: ISE is significantly correlated with learners' performance in emailing module.

\section{Method}

\subsection{Participants}

Non-probability, convenience sampling method was employed to choose 9 male and 31 female $(\mathrm{N}=40)$ lowerintermediate sophomores and juniors passing a course of advanced ESL writing in Karaj, Iran. Their age ranged from 19 to 25. Data were collected from two classes at Karaj Azad University. Twenty one participants formed the individual email group and 19 participants constituted the collaborative wiki group. Since the gender of the participants was not a relevant variable in this study, there was no control for sex variable.

\subsection{Instruments}

Prior to the treatment, a University of Tehran English Proficiency Test (UTEPT) was run to filter out the less proficient participants. Cronbach's alpha for the UTEPT was acceptable according to Nunnally's (1978) widely accepted cut-off of 0.60. $(\alpha=.84)$. As for the validity, Salehi and Rezaee (2008) used the design of multitrait-multimethod (MTMM) to investigate the construct validity of the UTEPT where two traits-grammar and vocabulary- and two methods-multiple choice and contextualization- were used. As they stated, this test was a high-stake test and the results of this test had a kind of life-changing implications for the test takers. It was found that the test possessed both convergent and discriminant validity. The cut off score for selection was $\% 70$ of the total score and 40 participants managed to meet the criterion and then they were divided into the two groups of wiki and emailing using convenience sampling method.

\subsubsection{General Internet Self-Efficacy (GISE) Measure}

GISE scale was adapted from the Torkzadeh and Van Dyke's (2001) ISE instrument to measure participants' perceived capability to use the internet by considering its limitations and the processes involved in the WWW applications (Hsu \& Chiu, 2004). The measure included 19 items on the general issues related to internet use with a composite reliability of 0.97 . A five-point Likert-type scale was used with options ranging from 1 which indicated strong disagreement to 5 indicating strong agreement.

\subsubsection{Writing Processes Rating Scale}

Maftoon and Akef (2010) developed a writing process rating scale with four different components that measured the four process stages of writing, namely brainstorming, outlining, drafting, and editing. The high inter-rater reliability 
estimate (0.895) indicated that their rating scales could produce consistent results.

\subsection{Wikispaces}

A wiki is generally defined as a "freely expandable collection of interlinked web pages, ahypertext system for storing and modifying information - a database, where each page is easily edited by any user with a forms-capable Web browser client" (Leuf \& Cunningham, 2001, p. 14). A wiki allows its users to rapidly and collaboratively develop content in a participatory manner. Wikispaces - a brand of wiki-was used in this study. Wikispaces is a data-base where students can easily log in and post their pieces of writing samples. The collaborative wiki module was based on Wikispaces.

\subsection{Writing Tasks}

Both wiki and emailing modules were assigned with the same writing tasks. The teacher specified a topic for the learners to write about. Each module accomplished the task based on the module requirement. For example, in Wikispaces, the learners had to accomplish the task by collaboratively building upon their peers' and teacher's contributions. However, in individualistic emailing task, learners were required to do the tasks on their own through email and the teacher was the only source of feedback.

\section{Data Collection}

This study was carried out in 16 sessions. In the first session, the teacher handed out the UT proficiency test and MSLQ pre-tests. The teacher introduced the course which was on the processes of writing namely brainstorming, outlining, drafting, and editing. He also gave the students a topic to write on at home, pinpointing that they should observe all the stages of process writing. Their writings were collected the following session and were rated using the general writing rating scale in order to assess students' writing level in the outset of the treatment.

In the second session, the teacher elaborated on the first two stages of writing processes (brainstorming and outlining) with a plethora of examples and exercises in order to dispel any doubts on the topic. In the third session, drafting and editing were taught to and elaborated for the students. It should be noted that the above-mentioned steps were common for both modules. From the third session on, the participants in each group provided an online writing sample each week.

\subsection{Collaborative Wiki Module}

This module was practiced on Wikispaces - one of the various brands of free wikis on the internet. In this module, participants did not sit together in one place and perform the tasks, but rather exercised collaboration from far distances through virtual environment. Wikispaces makes this remote give and take practical.

The procedure in this module was that the researcher (who is called an administrator in wiki environment) had sent an invitation from the Wikispaces website to all the participants' emails. Then, the participants had to accept the invitations through their emails at home and choose a username and password to be able to log in.

Each week the researcher posted a topic on the wiki and the participants were required to post their essays in all the four stages of process writing on the web. This module was collaborative in a way that each participant could build on his essay or comments based on the previous post. That means, the participants were required to carefully read what their peers had posted on the Wikispaces before they can put their own piece of writing on the wiki. In other words, the participants progressed through a chain-like collaborative written dialogue with an observer monitoring the whole process from above. However, although Wikispaces had the feature of uploading files and pictures when it came to posting mind map brainstorming and structuring, participants seemed reluctant to put time on the brainstorming and structuring sections of the writing processes and instead showed themselves more interested in drafting and editing other posts.

\subsection{Individualistic Email Module}
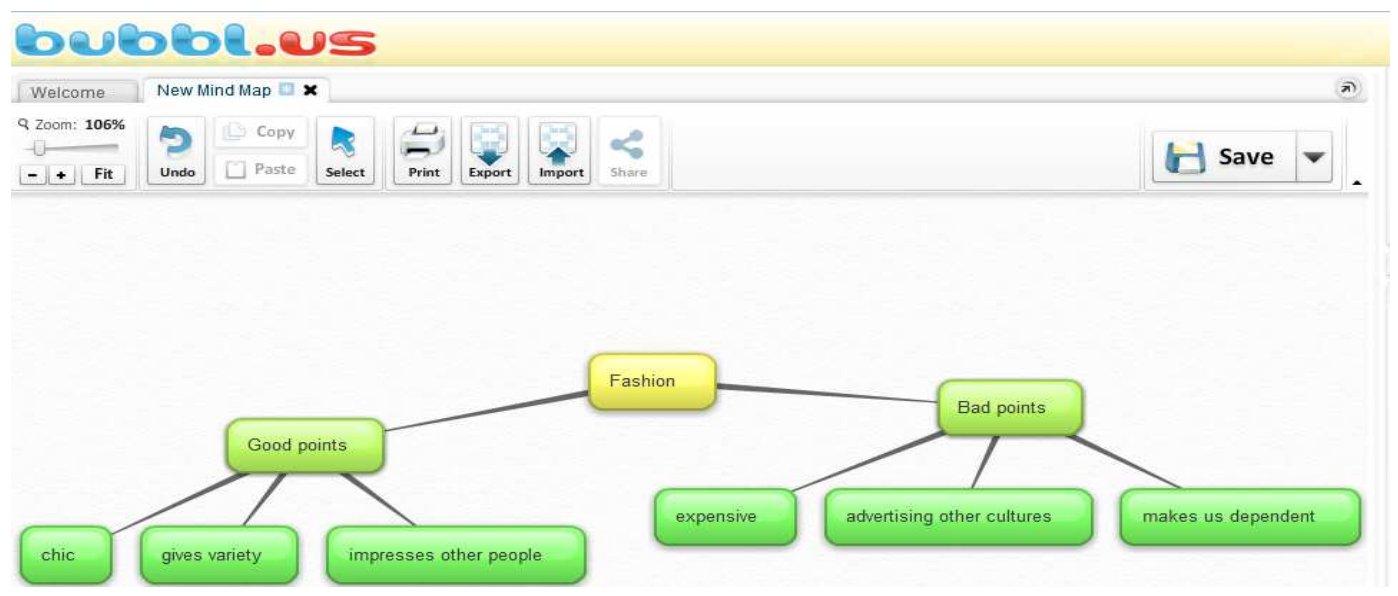

Figure 1. A Sample of Brainstorming Created in Email Environment. 
In this module participants went through all stages of process writing via the internet and email at home or from anywhere else. In this module, participants were required to prepare and send their essays via email every week (session). The brainstorming and the outlining sections were completed using online software called "bubbl.us". A sample of a brainstorming done by a participant in emailing module is illustrated in Figure 1. The participants simply copied the mind map and pasted it to their email file.

The researcher then received the attached documents individually and gave feedback on each using the "track changes" feature of Word Office Tool. Track Changes is a feature that allows the editor to edit or add comments on any part of the text. The edited version is then sent back to the participant to see and check his/her mistakes. Three more sessions were later added to the treatment, compensating for the possible time shortage.

\section{Results}

Pearson correlation coefficients were calculated to assess any significant relationship between students' ISE and their online writing performance in both wiki and emailing modules. According to results (Table 1), it can be concluded that ISE had significant correlation with the stages of online writing performance in both modules.

Table 1. Pearson Correlation for ISE and Components of Process Writing

\begin{tabular}{|c|c|c|c|}
\hline & & & ISE \\
\hline \multirow{15}{*}{ Wiki } & \multirow{3}{*}{ Brainstorming } & Pearson Correlation & $.705^{* *}$ \\
\hline & & Sig. (2-tailed) & .000 \\
\hline & & $\mathrm{N}$ & 40 \\
\hline & \multirow{3}{*}{ Outlining } & Pearson Correlation & $.576^{* *}$ \\
\hline & & Sig. (2-tailed) & .000 \\
\hline & & $\mathrm{N}$ & 40 \\
\hline & \multirow{3}{*}{ Editing } & Pearson Correlation & $.464^{* *}$ \\
\hline & & Sig. (2-tailed) & .000 \\
\hline & & $\mathrm{N}$ & 40 \\
\hline & \multirow{3}{*}{ Drafting } & Pearson Correlation & $.307^{* *}$ \\
\hline & & Sig. (2-tailed) & .005 \\
\hline & & $\mathrm{N}$ & 40 \\
\hline & \multirow{3}{*}{ Brainstorming } & Pearson Correlation & $.602^{* *}$ \\
\hline & & Sig. (2-tailed) & .001 \\
\hline & & $\mathrm{N}$ & 40 \\
\hline \multirow{9}{*}{ Emailing } & \multirow{3}{*}{ Outlining } & Pearson Correlation & $.522^{* *}$ \\
\hline & & Sig. (2-tailed) & .000 \\
\hline & & $\mathrm{N}$ & 40 \\
\hline & \multirow{3}{*}{ Editing } & Pearson Correlation & $.432^{* *}$ \\
\hline & & Sig. (2-tailed) & .003 \\
\hline & & $\mathrm{N}$ & 40 \\
\hline & \multirow{3}{*}{ Drafting } & Pearson Correlation & $.412^{* *}$ \\
\hline & & Sig. (2-tailed) & .000 \\
\hline & & $\mathrm{N}$ & 40 \\
\hline
\end{tabular}

**. Correlation is significant at the 0.01 level (2-tailed).
As displayed in Table 1, ISE was significantly correlated with brainstorming $(\mathrm{r}=.70, \mathrm{p}<0.01)$, outlining $(\mathrm{r}=.57$, $\mathrm{p}<0.01)$, editing $(\mathrm{r}=.46, \mathrm{p}<0.01)$, and drafting $(\mathrm{r}=.30, \mathrm{p}<0.01)$ in wiki module. Interestingly enough, ISE was also positively and significantly correlated with all stages of process writing in emailing module: brainstorming $(\mathrm{r}=.60, \mathrm{p}<0.01)$, outlining $(\mathrm{r}=.52, \mathrm{p}<0.01)$, editing $(\mathrm{r}=.43, \mathrm{p}<0.01)$, and drafting $(\mathrm{r}=.41$, $\mathrm{p}<0.01)$ respectively. Thus, it was concluded that participants' process writing performance in both online environments was an indicator of their ISE and their belief in their internet coping abilities. Therefore, both $\mathrm{H} 1$ and $\mathrm{H} 2$ hypotheses were held.

\section{Discussion}

The goal of the present study was to extend the current understanding of ISE in writing processes. In particular, we made an attempt to investigate the possible relationship between learners' ISE and their writing performance in two wiki and emailing modules.

In this study, learners' ISE was a determining factor in predicting learners' performance in the four stages of process writing in online modules. Learners could seemingly overcome any internet related struggle like logging into the wiki, posting their writing samples, giving feedback, uploading files, and downloading files. The more selfefficacious learners outperformed others in the stages of process writing in both modules. The finding might have been otherwise in the conventional settings of writing where even high self-efficacious learners had low writing performance (Igo, 2002; McCarthy, Meier, \& Rinderer, 1985; Pajares, 2002). In fact, they over-estimated their self-efficacy. However, in online environments, since the performance in writing largely depends on learners' abilities in dealing with technical stuff, a great number of studies have attested the high correlation between ISE and writing (Pajares \& Schunk, 2001).

The findings of the present study were consistent with the body of literature that highlights the importance of ISE in learning outcomes and processes (e.g. Chu \& Tsai, 2009; Hsu \& Chiu, 2004; Liang \& Tsai, 2008; Lu et al., 2007; Tsai \& Tsai, 2003; Yang, Tsai, Cho, Kim, \& Laffey, 2006; Yi \& Hwang, 2003).

Some other early studies also provided support for the relationship between computer self-efficacy and decisions involving computer usage and adoption such as coping with collaborative software and so forth (Compeau \& Higgins, 1995; Compeau \& Higgins, \& Huff, 1999; Davis, Bagozzi, \& Warsha, 1989; Hill, Smith, \& Mann, 1987; Igbaria \& Iivari, 1995).

This study also supported Joo et al. (2000) study who found that ISE was able to predict students' performance on online educational tasks in Web-based instruction (WBI). Eastin and LaRose (2000) showed that ISE was positively related to Internet usage in the context of Digital Divide. Eastin (2002) performed an analysis of the adoption of four 
ecommerce activities. Internet self-efficacy was only found to predict one of the four activities, i.e., online shopping. However, he suggested that task-specific self-efficacy could be considered a new variable in the adoption process.

Thompson, Higgins, \& Howell (2002) showed that taskspecific ISE had a significant effect on online search performance. Agarwal, Green, Grove, Evans, \& Schweik's (2000) research on computer self-efficacy also indicated that a significant positive relationship between software-specific self-efficacy and software usage. As they argued, E-service usage and Web specific self-efficacy should be directly related since we are more likely to attempt and persist in behavior that we feel capable of performing.

In this study, ISE was highly correlated with learners' writing performance in both modules. This might also be due to the strong relationship between ISE and confidence (Chang et al., 2014). That is to say, learners with higher levels of ISE showed more confidence and found the course more relevant than those with lower ISE.

Based on the findings of this study and many others, ISE should be encouraged and strengthened within online writing courses. In this way, learners will probably have better performance in each of the stages of process writing. However, an optimum level of ISE cannot and will not be achieved without taking the necessary measures. ISE can be better achieved if technophobic learners are encouraged to embrace more of the computers and the Internet; this is possible by requiring them to participate in training courses where they can come over their fear. This in effect will increase their self-efficacy. In addition, courses on the computer and internet education can be included in students' programs at the university. It will also be wiser if internet education takes place in the early stages of education at K-12 levels. This will bring about normalization (Bax, 2003) - a state where computers and the internet will be an integrated and inseparable part of our daily life.

\section{Conclusion}

This study investigated the effect of ISE on learners' writing performance in two wiki and emailing modules. ISE in online environments is on the beginning of its way. The positive relationship between ISE and online achievement in this study bestows corroborative evidence to the already well-established relationship observed in traditional learning settings (Hodges \& Kim, 2010). However, given the relatively small number of research studies investigating selfefficacy in online learning environments, still more work is needed in this area. It is not far from mind to imagine the positive effect of ISE on learners' online performance; but, what is of pivotal importance here is the question that how we as practitioners can and should lead our learners to better and harder embrace internet related tasks? What are the barriers? And how can they be removed?

It is important to explore and account for potential performance predictors, such as learners' cultural backgrounds, beliefs, values, and attitudes. Student-level variables such as support service, class size, learning style, personality, gender, student autonomy and other forms of interaction may be included and examined along with ISE in online learning environments (Juwah, 2006; Rodriguez Robles, 2006; Sahin, 2007).

Given the fact that ISE was observed as an effective factor in learners' online writing performance, teachers and practitioners will need to promote this self-regulatory strategy in online settings in particular, if they are to elicit more successful learning outcomes from their students in future.

\section{References}

[1] Agarwal, C., Green, G. M., Grove, J. M., Evans, T. P., \& Schweik, C. M. (2000). A review and assessment of land-use change models: Dynamics of space, time, and human choice. CIPEC Collaborative Report Series, 1, 1-84.

[2] Bandura, A. (1997). Self-efficacy: The exercise of control. New York: W.H. Freeman and Company.

[3] Bax, S. (2003). CALL- past, present and future. System, 31(1), 13-28.

[4] Bell, P. D. (2007). Predictors of college student achievement in undergraduate asynchronous web-based courses. Education, $127,523-533$.

[5] Chang, C., Liu, E., Sung, H., Lin, C., Chen, N., \& Cheng, S. (2014). Effects of online college student's Internet selfefficacy on learning motivation and performance. Innovations in Education and Teaching International Education and Teaching International, 51 (4), 366-377.

[6] Chao, Y. C. J., \& Lo, H. C. (2011). Students' perceptions of Wiki-based collaborative writing for learners of English as a foreign language. Interactive Learning Environments, 19, 395411.

[7] Chu, R. J. C., \& Tsai, C. C. (2009). Self-directed learning readiness, Internet self-efficacy and preferences towards constructivist Internet-based learning environments among higher-aged adults. Journal of Computer Assisted Learning, 25, 489-501.

[8] Compeau, D. R., \& Higgins, C. A. (1995). Computer selfefficacy: Development of a measure and initial test. MIS Quarterly, 19, 189-211.

[9] Compeau, D. R., Higgins, C. A., \& Huff, S. (1999). Social cognitive theory and individual reaction to computing technology: A longitudinal study. MIS Quarterly, 23(2), 145158.

[10] Davis, F. D., Bagozzi, R. P., \& Warshaw, P. R. (1989). User acceptance of computer technology: A comparison of two theoretical models. Management Science, 35 (8), 982-1002.

[11] Eastin, M.S. (2002). Diffusion of e-commerce: An analysis of the adoption of four e-commerce activities. Telematics and Informatics, 19, 251-267.

[12] Eastin, M. A., \& LaRose, R. L. (2000). Internet self-efficacy and the psychology of the digital divide. Journal of Computer Mediated Communication, 6 (1), 22-40. 
[13] Flowers, L. O. (2011). Exploring HBCU student academic self-efficacy in online STEM courses. The Journal of Human Resource and Adult Learning, 7 (2), 139-145.

[14] Greenfield, R. (2003). Collaborative e-mail exchange for teaching secondary ESL: A case study in Hong Kong. Language Learning \& Technology, 7 (1), 46-70.

[15] Hill, T., Smith, N. D., \& Mann, M. F. (1987). Role of efficacy expectations in predicting the decision to use advanced technologies: The case of computers. Journal of Applied Psychology, 72, 307-313.

[16] Hodges, C. B., \& Kim, C. (2010). Email, self-regulation, selfefficacy, and achievement in a college online mathematics course. Journal of Educational Computing Research, 43 (2), 207-223.

[17] Hsu, M. H., \& Chiu, C. M. (2004). Internet self-efficacy and electronic service acceptance. Decision Support Systems, 38, 369-381.

[18] Igbaria, M., \& Livari, J. (1995). The effect of self-efficacy on computer usage. Omega International Journal of Management Science, 23 (6), 587- 605.

[19] Igo, L. B. (2002). The accuracy of self-efficacy: A comparison of high school and college students. Academic Exchange Quarterly, 6 (10), 70-85.

[20] Joo, Y., Bong, M., \& Choi, H. (2000). Self-efficacy for selfregulated learning, academic self-efficacy, and Internet selfefficacy in Web-based instruction. Educational Technology Research and Development, 48 (2), 5-17.

[21] Juwah, C. (2006). Introduction. In C. Juwah (Ed.), Interactions in online education: Implications for theory and practice (pp. 1-5). New York: Routledge.

[22] Kessler, G. (2009). Student-initiated focus to form in wikibased collaborative writing. Language Learning \& Technology, 13(1), 79-95. Retrieved June 15, 2014, from: http://lt.msu.edu/vol13num1/kessler.pdf

[23] Kim, Y. H., \& Kim, D. J. (2005). A study of online transaction self-efficacy, consumer trust, and uncertainty reduction in electronic commerce transaction. Proceedings of the 38th Hawaii International Conference on System Sciences.

[24] Kost, C. (2011). Investigating writing strategies and revision behavior in collaborative wiki projects. CALICO Journal, 28 (3), 606-620.

[25] Lee, L. (2010). Exploring wiki-mediated collaborative writing: A case study in an elementary Spanish course. CALICO Journal, 27 (2), 260-276. Retrieved April 8, 2014, from: https://calico.org/journalTOC.php.

[26] Lee, J., \& Medlinger, S. (2011). Perceived self-efficacy and its effect on online learning acceptance and student satisfaction. Journal of Service Science and Management, 4, 243-252

[27] Leuf, B., \& Cunningham, W. (2001). The wiki way: Quick collaboration on the web. Boston, MA: Addison-Wesley Longman.

[28] Liang, J. C., \& Tsai, C. C. (2008). Internet self-efficacy and preferences toward constructivist internet-based learning environments: A study of pre-school teachers in Taiwan. Educational Technology \& Society, 11(1), 226-237.

[29] Lu, E.Y., Ma, H., Turner, S., \& Huang, W. (2007). Wireless
Internet and student-centered learning: A partial least-squares model. Computers and Education, 49, 530-544.

[30] Lynch, R., \& Dembo, M. (2004). The relationship between self-regulation and online learning in a blended learning context. International Review of Research in Open and Distance Learning. Retrieved Febrauary 2014 from: http://www.irrodl.org/content/v5.2/lynch-dembo.html.

[31] Maftoon, P., \& Akef, K. (2010). Developing rating scale descriptors for assessing the stages of writing process: The constructs underlying learners' performance. Journal of Language and Translation, 1(1), 1-18.

[32] Marakas, G., Yi, M., \& Johnson, R. (1998). The multilevel and multifaceted character of computer self-efficacy: Toward clarification of the construct and an integrative framework for reason. Information Systems Research, 9 (2), 126-163.

[33] McCarthy, P., Meier, S., \& Rinderer, R. (1985). Self-efficacy and writing: A different view of selfevaluation. College Composition and Communication. 36, 465-471.

[34] Miltiadou, M., \& Yu, C. (2000). Validation of the online technologies self-efficacy scale (OTSES). Information Systems Research, 11(1), 101-121.

[35] Nunnally, J. (1978). Psychometric theory. New York: McGraw-Hill.

[36] Pajares, F. (2002). Overview of social cognitive theory and of self-efficacy. Retrieved September 10, 2014, from: www.emory.edu/education/mfp/eff.html.

[37] Pajares, F., \& Schunk, D. H. (2001). Self-beliefs and school success: Self-efficacy, self-concept, and school achievement. In R. Riding \& S. Rayner (Eds.), perception (pp. 239-266). London: Ablex Publishing.

[38] Puzziferro, M. (2008). Online technologies self-efficacy and self-regulated learning as predictors of final grade and satisfaction in college-level online courses. The American Journal of Distance Education, 22, 72-89.

[39] Rodriguez Robles, F. M. (2006). Learner characteristic, interaction and support service variables as predictors of satisfaction in Web-based distance education. Dissertation Abstracts International, 67(7), 12-32.

[40] Sahin, I. (2007). Predicting student satisfaction in distance education and learning environments. ERIC Document Reproduction Service, 23-43.

[41] Salaber, J. (2014). Facilitating student engagement and collaboration in a large postgraduate course using wiki-based activities. The International Journal of Management Education, 12 (2), 115-126.

[42] Salehi, M., \& Rezaee, A. (2009). On the factor structure of the grammar section of university of Tehran English Proficiency Test. Indian Journal of Applied Linguistics. 35 (2), 169-187.

[43] Tharp, T. L. (2010). Wiki, wiki, wiki-what? Assessing online collaborative writing. English Journal, 99 (5), 40-46

[44] Thompson, R. L., Higgins, C. A. \& Howell, J. M. (2002). Personal computing: Toward a conceptual model of utilization. MIS Quarterly, 15(1), 125-143.

[45] Torkzadeh, G., \& Van Dyke, T. P. (2001). Development and validation of an Internet self-efficacy scale. Behaviour and Information Technology, 20 (4), 275-280. 
[46] Tsai, M. J., \& Tsai, C. C. (2003). Information searching strategies in web-based science learning: The role of Internet self-efficacy. Innovations in Education and Teaching International, 40, 43-50.

[47] Vygotsky, L. S. (1978). Mind in society: The development of higher psychological processes. Cambridge, MA: Harvard University Press.

[48] Wang, A. Y., \& Newlin, M. H. (2002a). Predictors of webstudent performance: The role of self- efficacy and reasons for taking an on-line class. Computers in Human Behavior, 18 (2), $151-163$.

[49] Wang, A. Y., \& Newlin, M. H. (2002b). Predictors of performance in the virtual classroom. The Journal Online, 29 (10), 121-133. Retrieved November 14, 2014, from: http://www.thejournal.com/magazine/vault/A4023.cfm

[50] Yang, C. C., Tsai, I. C., Cho, M. H., Kim, B., \& Laffey, J. (2006). Exploring the relationships between students' academic motivation and social ability in online learning environments. Internet and Higher Education, 9 (4), 277-286.

[51] Yi, M .,\& Hwang, Y. Y. (2003). Predicting the use of webbased information systems: self-efficacy, enjoyment, learning goal orientation, and the technology acceptance model. International Journal of Human-Computer Studies, 59, 431449.
[52] Xie, K., Debacker, T. K., \& Perguson, C. (2006). Extending the traditional classroom through online discussion: The role of student motivation. Journal of Educational Computing Research, 34, 67-89.

[53] Zhang, J., Li, F., Duan, C., \& Wu, G. (2001). Research on selfefficacy of distance learning and its influence to learners' attainments. Retrieved November 14, 2014, from http://www.icce2001.org/cd/pdf/p13/CN100.pdf

[54] Dr Amin Shahini received his PhD in TEFL from Islamic Azad University, Science and Research Branch. He received his MA and BA from the University of Tehran. He is currently a faculty member at Imam Sadigh University. His area of interest is CALL and Discourse Analysis and has published some articles in this regard in national and international journals.

[55] Dr Majid Nemati received his PhD in applied Linguistics. He is currently an Assistant Professor at the University of Tehran. His area of interest includes applied linguistics, writing, ESP and first language acquisition. He has published a number of articles both in national and international journals and has given lectures in a number of local and international conferences. 